\title{
Changes in ascending aorta dimensions, aortic valve function and systolic ventricular function over time in patients with congenital aortic stenosis
}

\author{
Alexia Rossi, Denise van der Linde, Tirza Springeling, Adriaan Moelker, Gabriel P Krestin, Robert J van Geuns, \\ Jolien Roos-Hesselink
}

From 2011 SCMR/Euro CMR Joint Scientific Sessions

Nice, France. 3-6 February 2011

\section{Introduction}

Bicuspid aortic valve (BAV) is one of the most common congenital heart malformations and is a frequent cause of aortic valve stenosis (AoS).

\section{Purpose}

The aim of this study was to evaluate the progression of aortic dilatation, aortic valve function, and ventricular function in patients with congenital AoS.

\section{Methods}

Twenty-five patients with congenital AoS were prospectively followed with ECG-gated cine-MRI. Aortic root and ascending aorta diameters were measured. Peak aortic velocity and mean gradient were assessed using a retrospectively gated phase contrast sequence. Left ventricular hemodynamic parameters and myocardial mass were calculated using steady-state free precession images.

\section{Results}

Sixteen men and 9 women were included in the study (mean age $32.6 \pm 7.6$ years). The mean time $( \pm \mathrm{SD})$ between baseline and follow-up study was $33.7 \pm 6.1$ months. During follow-up aortic diameters significantly increased at aortic annulus by $1.4 \mathrm{~mm}(\mathrm{p}=0.014)$, at sinus of Valsava by $2.0 \mathrm{~mm}(\mathrm{p}=0.003)$ and at ascending aorta level by $2.0 \mathrm{~mm}$ $(p<0.001)$. No significant increase in sinotubular-junction diameter was observed. Peak velocity significantly increased from $329.1 \pm 70.2 \mathrm{~cm} / \mathrm{s}$ at baseline to 353.4 $\pm 82.6 \mathrm{~cm} / \mathrm{s}$ at follow-up with a mean progression of
$8.0 \mathrm{~cm} / \mathrm{s} /$ year. Mean aortic valve gradient increased significantly from baseline to follow-up: $44.5 \pm 18.6$ vs $53.5 \pm 25.3$ $\mathrm{mmHg}(\mathrm{p}=0.021)$. Ejection fraction significantly increased from $57.6 \pm 6.4$ to $59.7 \pm 7.1 \%(\mathrm{p}=0.001)$ and a significant increase of myocardial ventricular mass was observed from $129.2 \pm 36.2$ at baseline to $132.9 \pm 37.8$ grams at follow-up $(\mathrm{p}=0.015)$.

\section{Conclusions}

After a mean follow-up of 33 months a progression of aortic diameter dilation, aortic peak velocity, mean gradient and ventricular mass occurred in adult patients with congenital AoS.

Published: 2 February 2011

doi:10.1186/1532-429X-13-S1-P211

Cite this article as: Rossi et al:: Changes in ascending aorta dimensions, aortic valve function and systolic ventricular function over time in patients with congenital aortic stenosis. Journal of Cardiovascular Magnetic Resonance 2011 13(Suppl 1):P211. 